This document is the unedited Author's version of a Submitted Work that was subsequently accepted for publication in the Journal of the American Chemical Society, copyright (C) American Chemical Society, after peer review. To access the final edited and published work see

http://dx.doi.org/10.1021/jacs.6b04776 


\title{
Multicolor Photoluminescence Including White-Light Emission by a Single Host-Guest Complex
}

\author{
Qi-Wei Zhang, ${ }^{+, \neq, \neq}$Dengfeng Li, ${ }^{+, *}$ Xin Li, ${ }^{\S}$ Paul B. White, ${ }^{\ddagger}$ Jasmin Mecinović, ${ }^{\ddagger}$ Xiang Ma, ${ }^{*,+}$ Hans Ågren, ${ }^{\S}$ Roe- \\ land J. M. Nolte, ${ }^{\ddagger}$ and He Tian ${ }^{*,+}$ \\ ${ }^{+}$Key Laboratory for Advanced Materials and Institute of Fine Chemicals, College of Chemistry and Molecular Engineering, East Chi- \\ na University of Science and Technology, Meilong road 130, Shanghai 200237, P. R. China \\ ${ }^{\ddagger}$ Radboud University, Institute for Molecules and Materials, Heyendaalseweg 135, 6525 AJ Nijmegen, The Netherlands \\ ${ }^{\varsigma}$ Division of Theoretical Chemistry and Biology, School of Biotechnology, KTH Royal Institute of Technology, SE-10691 Stockholm, \\ Sweden
}

\begin{abstract}
Achieving multicolor photoluminescence especially white-light emission under mild conditions based on a single fluorescent compound is a great challenge. Herein, we report a novel colorful-emission host-guest complex BPCY, which is composed of a two-arm fluorescent guest molecule (BPC) and $\gamma$-cyclodextrin $\left(\gamma\right.$-CD) as the host molecule. BPC bears a unique asymmetrical donor-acceptor-donor $\left(D_{1^{-}}\right.$ $\left.A^{+} \sim D_{2}\right)$ type structure, where $D_{1}, A^{+}, D_{2}$ stand for the binaphthol electron donor, pyridinium electron acceptor, and coumarin electron donor, respectively. The luminescence property of BPC shows dual-sensitivity, i.e. toward the excitation wavelength and the cyclodextrin host molecule. Under certain conditions the complex shows three different emission wavelengths allowing the realization of multicolor photoluminescence, including red (R), green (G), blue (B) and the various intermediate colors by orthogonally modulating these two stimuli. In this way, nearly pure white-light emission with CIE coordinates $(0.33,0.34)$ could be generated. A combination of structural, spectroscopic, and computational simulation studies revealed the occurrence of synergetic mechanistic processes for the stimuli-responsive multicolor luminescence of the BPCY complex, namely host-enhanced intramolecular charge-transfer (ICT) and host-induced restriction of intramolecular rotation (RIR). This new supramolecular complex with superior multicolor emission abilities may find wide applications in the fields of information processing and display media. Furthermore the molecular design rationale presented here may provide a new design strategy for the development of high performance optical materials using a single supramolecular platform.
\end{abstract}

\section{INTRODUCTION}

Noncovalent interactions, as widely employed in supramolecular chemistry, are increasingly used as a design tool to organize different types of molecules into unique architectures with precisely controlled structures and functions. ${ }^{1}$ One of the fields where supramolecular chemistry may play an important role is the development of materials that display multicolor photoluminescence (PL) switching triggered by external stimuli. These materials have recently attracted a lot of research interest because they can be used in diverse applications, e.g. in logic gates, molecular machines, switches, and optical-sensors. ${ }^{2}$ In particular, luminescent assemblies of molecules that can be tuned for whitelight emission are of major importance because of their potential applications in lighting devices and display media. ${ }^{3}$ Indeed, many organic luminophores, taking aggregation-induced-emission (AIE) compounds as an example, show diverse light-emitting behaviors in different aggregation states which are normally controlled by concentration, temperature, solvent polarity, etc. ${ }^{4}$ So far, several chemical systems have been successfully developed towards the goal of multicolor emission. They are based on small molecules, ${ }^{5}$ polymers, ${ }^{6}$ metal-organic framworks, ${ }^{7}$ quantum dots, $^{8}$ and nanoparticles, ${ }^{9}$ using e.g. photo irridiation, ${ }^{10}$ solvent polarity change, ${ }^{11}$ and mechano/thermal stimuli, ${ }^{12}$ as control parameters. In this connection, supramolecular chemistry may open new avenues to the design of luminescence-tunable nanostructures, i.e. by taking advantage of the fact that the optical properties of the composite can be adjusted via noncovalent interactions. However, only very few supramolecular interactions, such as hydrogen-bonding, metalligand coordination, and $\pi-\pi$ stacking, have been used to achieve photoluminescence tunable systems, especially white-lightemitting materials. ${ }^{13}$ Nevertheless, most of the dual-emission systems can only alter the intensity ratio of the two emission peaks hence the luminescence color changes are generally limited, that is, only switching quasi-linearly from one spot to the other spot in the CIE chromaticity diagram is achieved. Otherwise, multicolor emission materials usually need the hybridization or doping of different fluorescent dyes.

In recent years, we have reported several color-tunable luminescent materials based on the tailored modification of core fluorophores by taking advantage of various mechanisms such as aggregation-induced-emission, ${ }^{14}$ vibration controlled color change, ${ }^{15}$ and electronic/structural relaxation induced multifluorescence. ${ }^{16}$ We have also developed supramolecular systems with stimuli-responsive properties based on host-guest interactions between binaphthol (BN) derivatives, coumarins, and cyclodextrins (CDs). ${ }^{17}$ The latter molecules consist of six ( $\left.\alpha-C D\right)$, seven $(\beta-C D)$, eight $(\gamma-C D)$, or more glucopyranose units and have become one of the most widely used building blocks in supramolecular chemistry due to the fact that their hydrophobic cavities allow the selective encapsulation of guest molecules in 
water. ${ }^{18}$ Encouraged by these previous studies and with an intention to construct a PL tunable system through a supramolecular approach, we designed a novel two-arm donoracceptor-donor $\left(D_{1}-A^{+} \sim D_{2}\right)$ fluorophore BPC, bearing a chiral pyridinium binaphthol moiety (PBN) as the electron donoracceptor moiety and a coumarin group at the end of each arm acting as the other electron donor and supramolecular binding unit. The latter groups are attached via flexible alkyl chains (Scheme 1). We show here that the PL emission wavelength and intensity of BPC can be orthogonally switched by changing the excitation wavelength and by applying host-guest interactions. In this way, we conveniently realized truely colorful PL emission including whitelight, using a single supramolecular host-guest complex.

\section{RESULT AND DISCUSSION}

Scheme 1. Synthesis of the multicolor-emission fluorophore BPC and the structures of reference compounds BPM, NPC, and PC.
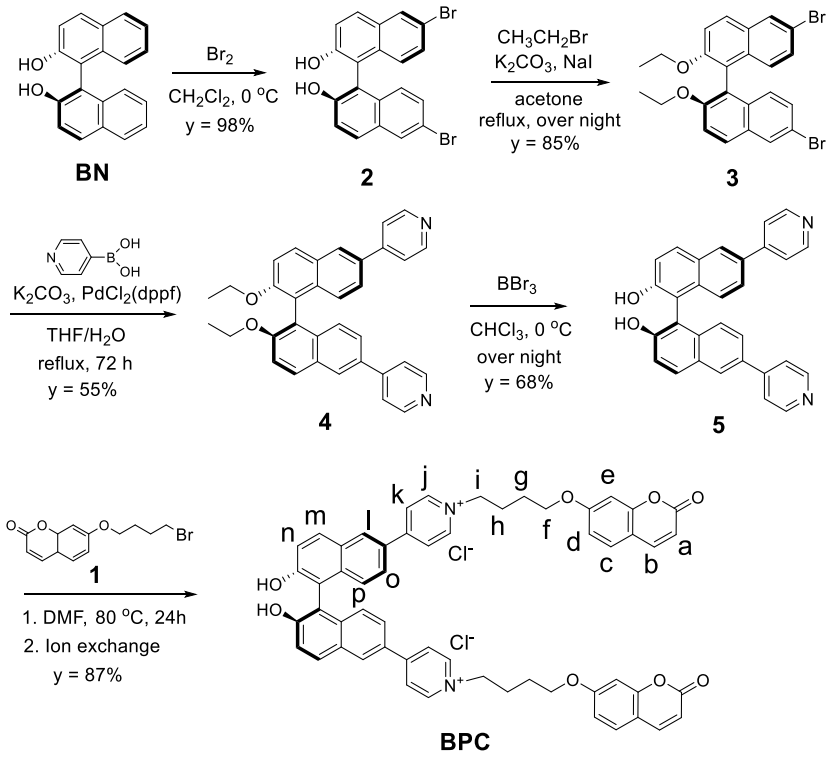

Reference Compounds:

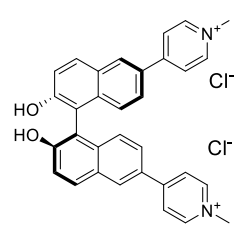

BPM

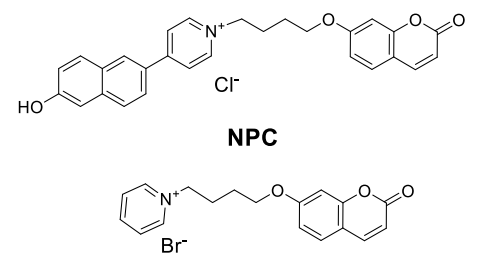

PC
Synthesis. (R)-(+)-1,1'-Bi(2-naphthol) (BN) was brominated at the 6,6 ' positions by reaction with bromine in dichloromethane at 0 ${ }^{\circ} \mathrm{C}$ to yield compound 2 . Protection of the hydroxyl groups of 2 by bromoethane gave compound 3, which was subsequently converted into the $\mathrm{PBN}$ derivative $\mathbf{4}$ and afterwards deprotected to give $\mathbf{5}$ by using $\mathrm{BBr}_{3}$ at $0{ }^{\circ} \mathrm{C}$ in chloroform. The target product $\mathrm{BPC}$ with chloride as counter anions was finally achieved by coupling of $\mathbf{5}$ with alkoxyl coumarin $1,{ }^{17 b}$ followed by ion exchange (Scheme 1). The reference compounds BPM, NPC and PC were prepared using similar procedures as detailed in the Supporting Information (SI).

Binding studies. To obtain information on how the designed fluorophore BPC interacts with $\gamma$-CD and to study the thermodynamics of the host-guest interactions, we first performed
UV-vis binding studies and constructed a Job plot based on the measured UV-vis absorption spectra (Figure S1 in SI). These experiments indicated that, BPC and $\gamma$-CD interacted in a $1: 1$ hostguest binding stoichiometry. Furthermore, isothermal titration calorimetry (ITC) measurements were conducted in aqueous solutions. As shown in Figure 1a, these ITC experiments clearly demonstrated the occurrence of a strong 1:1 binding interaction between BPC and $\gamma-\mathrm{CD}$ in water with an association constant of $\mathrm{K}_{\mathrm{a}}$ $(3.3 \pm 0.4) \times 10^{4} \mathrm{M}^{-1}$, while under the same conditions BPC did not show any binding affinity for $\beta-C D$ (Figure $1 b$ ). The latter result is quite unexpected because the cavity of $\beta-C D$, although being smaller than that of $\gamma$-CD, is surely large enough to encapsulate the coumarin unit, ${ }^{19}$ a result that is also confirmed by 2 D ROESY NMR measurements. As seen in Figure S2 (in SI) BPC shows no interaction with $\beta-C D$, while strong rotating-frame nuclear overhauser effect (ROE) signals are found between the protons of the coumarin moiety of the reference compound PC and the internal protons of $\beta$-CD. Such a significant difference in binding behaviour is very intriguing and stimulate us to investigate in-depth the exact structure and binding properties of BPC, which will be discussed in the following sections.
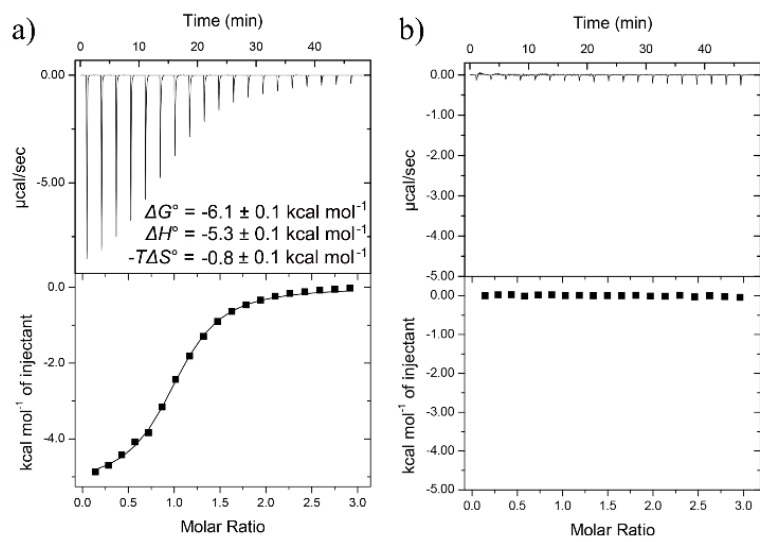

Figure 1. ITC data for BPC with a) $\gamma$-CD and b) $\beta$-CD in water, [BPC] $($ cell $)=500 \mu \mathrm{M},[\gamma-\mathrm{CD}]=[\beta-\mathrm{CD}]($ syringe $)=6.0 \mathrm{mM}$.

Further evidence for the formation of a 1:1 host-guest complex came from diffusion-ordered NMR spectroscopy (DOSY). The diffusion coefficients $(D)$ for the guest BPC, the host $\gamma$-CD, and the $1: 1$ complex BPCY were measured to be $2.31 \times 10^{-10} \mathrm{~m}^{2} / \mathrm{s}, 2.53$ $\times 10^{-10} \mathrm{~m}^{2} / \mathrm{s}$, and $2.15 \times 10^{-10} \mathrm{~m}^{2} / \mathrm{s}$, respectively (Figure S3, SI). The small decrease in the diffusion constant of $\gamma$-CD upon binding BPC is consistent with the formation of a 1:1 complex as the calculated change in molecular weight $(M W)$ ratio $\left(M W_{\text {host }} / M W_{\text {complex }}\right)$ from the measured $D$ values, assuming spherical shape, stable density and viscosity, was found to be 0.61 , which is close to the expected $M W$ ratio based on a 1:1 complex (0.59). Final evidence for 1:1 host-guest complex formation, was provided by ESI-MS spectrometry (Figure S4, SI). A strong peak at 1085.7 corresponding to the $[\mathrm{BPC}+\gamma-\mathrm{CD}-2 \mathrm{Cl}]^{2+}$ ion was observed and further isotopic pattern analysis showed a perfect matching between the measured and calculated mass peaks for this double-charged 1:1 complex (Figure $2 \mathrm{a}$ and $2 \mathrm{~b}$ ). 

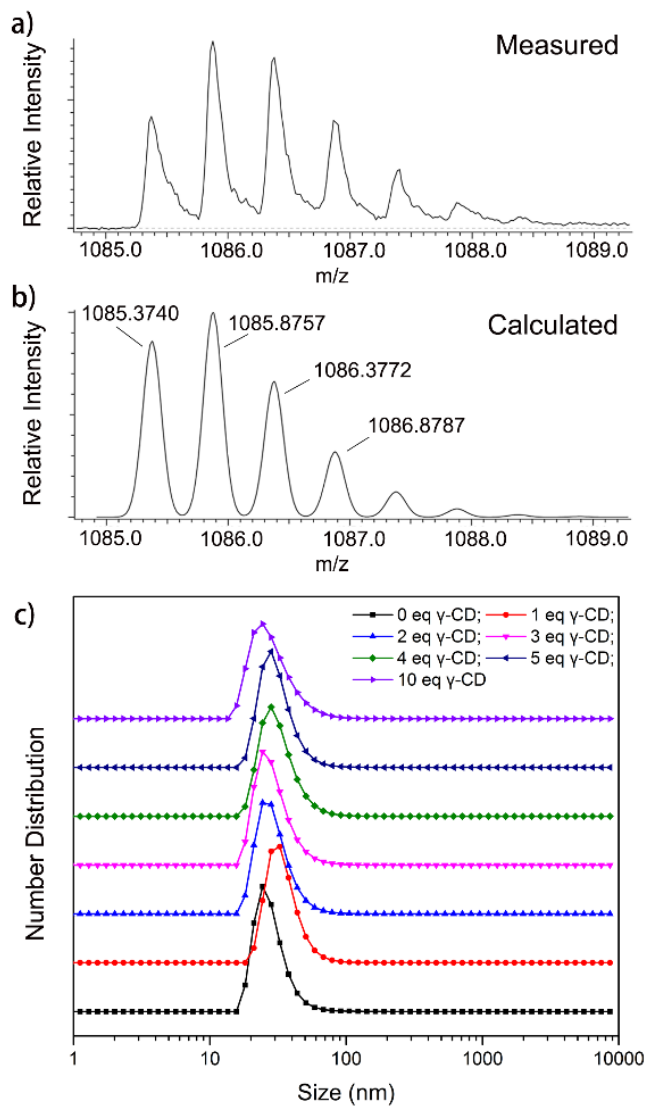

Figure 2. a) $D_{H}$ values of aqueous BPC solutions containing various amounts of $\gamma$-CD as measured by DLS, $[\mathrm{BPC}]=0.04 \mathrm{mM}, 25^{\circ} \mathrm{C}$; b) measured and c) calculated mass spectra of BPCY.

The formation of a host-guest complex (BPCY) between $\gamma$-CD and BPC with a measured ratio of 1:1 means that we are dealing with either a $1: 1$ complex or the $n: n$ aggregates. To verify these different possibilities, dynamic light-scattering (DLS) measurements were carried out. The average hydrodynamic diameters $\left(D_{H}\right)$ of BPC solutions containing various equivalences (equiv.) of $\gamma$-CD were recorded and compared. As shown in Figure $2 c$, the $D_{H}$ values almost remained constant when the amounts of $\gamma$-CD were changed from 0 to 10 equiv. Considering the amphiphilic structure of BPC and the size measured by DLS (ca. $20 \sim 40 \mathrm{~nm}$ ), we suppose that there may be some kind of aggregates (such as micelles) in the BPC solution, and the independence of the $D_{H}$ value of BPC on the presence of the host molecule $\gamma$-CD indicates that the binding with $\gamma$-CD doesn't change the size much for these aggregates. Transmission electron microscopy (TEM) was used to visualize the aggregates. As shown in Figure S5 in SI, aggregates (micelles) with similar size and shape $(20 \sim 40 \mathrm{~nm})$ can be observed both for BPC and BPCY, indicating that the aggregated BPC can still interact with $\gamma$-CD and the binding with $\gamma$-CD doesn't change the size much for the BPC aggregates (Figure S6, SI), which is also in accordance with the DLS results. Next, the electrical conductivity measurement at various concentrations at $25{ }^{\circ} \mathrm{C}$ was conducted to determine the critical micelle concentration (CMC) of BPC. According to plot in Figure S7 in SI, the CMC was measured as around $4 \mu \mathrm{M}$, which rationalized the existence of aggregates in solution at $40 \mu \mathrm{M}$.

After a series of measurements and analysis presented in the flowing sections, we deduce that the BPC micelle is most likely a kind of loose and dynamic aggregate because no obvious interactions can be observed between BPC molecules in the ground and excited states in the experimental condition. We also demonstrated that $\gamma$-CD modulated the optical property of BPC solution by the same mechanism either in the dispersed or aggregated states of BPC molecules, so the luminescence behavior observed in this work is not induced by the aggregation of BPC, but mainly originates from the fundamental interactions in the single host-guest complex.

Structural characterization of the host-guest complex. Firstly, all NMR resonances of the guest BPC and the complex BPCY were unequivocally assigned with the aid of 2D NMR techniques including COSY, HSQC and ROESY (Figure S8-S13, SI). The intramolecular rotation of the BPC molecule appears to be quite restricted, as judged from the remarkable broadening of all proton peaks of BPC, after the addition of $\gamma$-CD (Figure S8 and S12, SI). These signals gradually became sharper when the temperature was raised due to the enhanced molecular motion (Figure S14, SI). A similar restriction of intramolecular rotation (RIR) could be achieved by gradually reducing the temperature of the BPC solution itself, as indicated by the broadening of the proton signals in the NMR spectra (Figure S15, SI). To study the effect of concentration on the system, ${ }^{1} \mathrm{H}$ NMR experiments with BPC and BPCY at different concentrations in water were performed at room temperature. As presented in Figure S16 and Figure S17 in SI, all the peaks of the guest molecule BPC remained sharp even at the highest applied concentration of $1.0 \mathrm{mM}$, which is almost the saturated concentration of BPC in water. On the contrary, all the peaks of the complex BPCY maintained their broadness even at $0.05 \mathrm{mM}$, which is almost the lowest detectable concentration of this compound by NMR in water and close to the concentration used in the optical measurements $(0.04 \mathrm{mM}$, vide infra). These results indicate that the broadening of the proton peaks in the NMR spectra is not caused by the intermolecular aggregation of BPC, but the result from the host-guest binding between BPC and $\gamma$-CD. In addition to these observations, the ROESY spectrum of BPC at room temperature (Figure S11, SI) showed some weak but clearly visible cross peaks between protons $\mathrm{H}_{\mathrm{j}}, \mathrm{H}_{\mathrm{k}}$ of the pyridinium group and protons $\mathrm{H}_{\mathrm{d}}, \mathrm{H}_{\mathrm{e}}$ of the coumarin group, which indicates the existence of ROEs between these protons. These ROE contacts indicate the adjacency of the pyridinium and coumarin units, which is quite remarkable since they are far away in the stretched BPC molecule (Scheme 1). Similar but stronger ROE signals were also found in the ROESY spectrum of the complex BPCY even at $60^{\circ} \mathrm{C}$ (the temperature at which sharp peaks conductive to analysis could be obtained). As shown in Figure 3, besides the correlations of $\mathrm{H}_{\mathrm{j}}$, $\mathrm{H}_{\mathrm{k}}$ with $\mathrm{H}_{\mathrm{d}}, \mathrm{H}_{\mathrm{e}}$, and $\mathrm{H}_{\mathrm{a}}$ with $\mathrm{H}_{\mathrm{p}}$, additional signals could be found between the protons of BPC and $\gamma$-CD. These abnormal correlations point to a self-folding structure, as visible in the simulated structure (Figure 4) by density functional theory (DFT) and molecular dynamics (MD) calculations (vide infra). As can be seen in Figure 4, the coumarin groups fold back and stack with the PBN unit probably because of hydrophobic effects, $\pi-\pi$ stacking, and donor-acceptor interactions. The size of this self-folded structure nicely matches the cavity of $\gamma$-CD leading to strong binding, which in turn enhances and fixes the self-folded conformation as indicated by the broad peaks in the ${ }^{1} \mathrm{H}$ NMR spectrum (Figure S12, SI). 


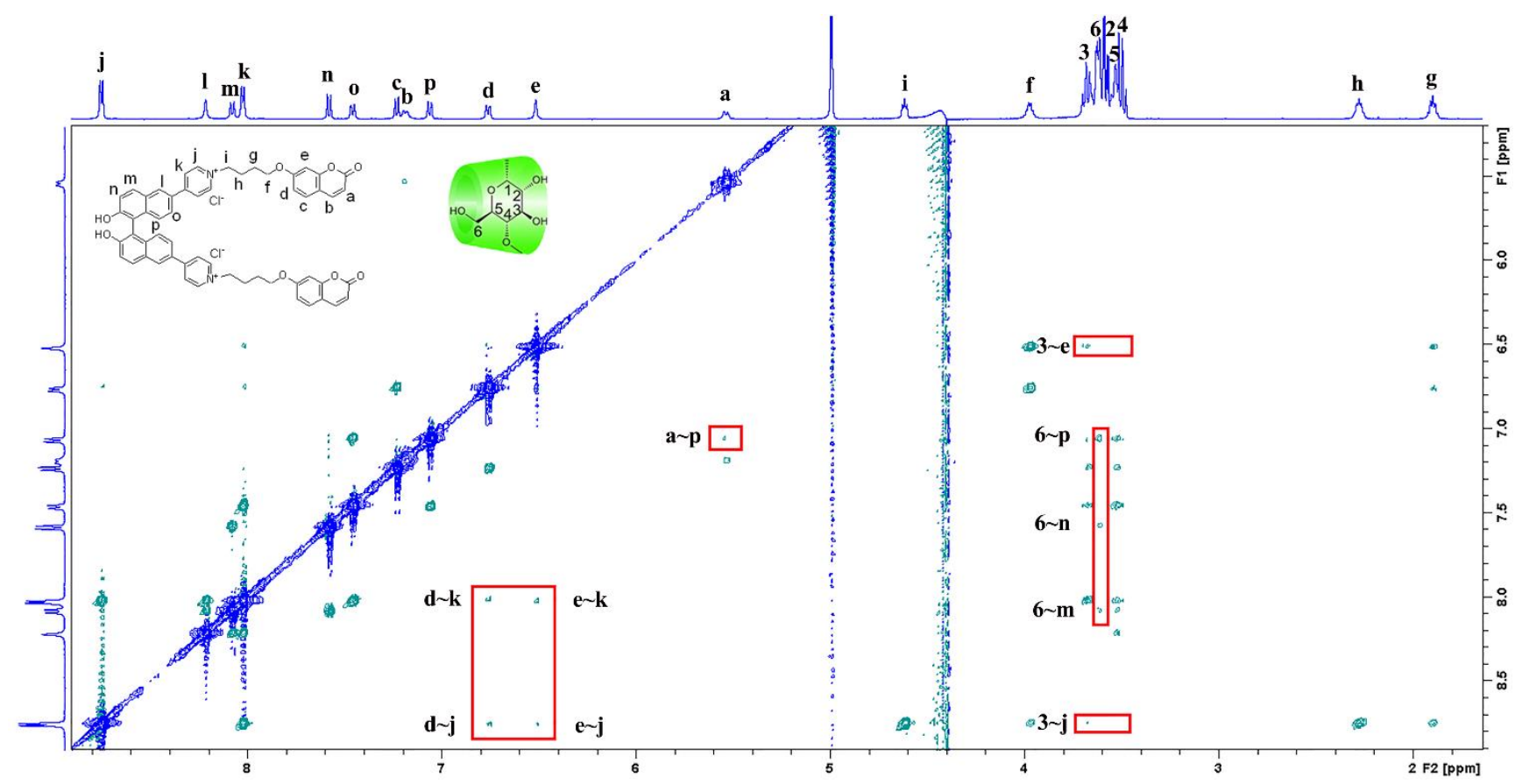

Figure 3. 2D ROESY NMR spectrum of the complex BPCY, in which $[\mathrm{BPC}]=[\gamma-\mathrm{CD}]=0.8 \mathrm{mM}$ in $\mathrm{D}_{2} \mathrm{O}$ at $60^{\circ} \mathrm{C}$ with water suppression.

In order to get an idea about the direction of the encapsulation of BPC by $\gamma$-CD, the ROESY spectrum was analyzed more carefully. As shown in Figure 3, the internal proton $\mathrm{H}_{3}$ near the wide rim of $\gamma$-CD is positioned close to the proton $\mathrm{H}_{e}$ of the coumarin and proton $\mathrm{H}_{\mathrm{j}}$ of the pyridinium groups. On the other hand, proton $\mathrm{H}_{6}$ from the narrow rim of $\gamma$-CD is close to protons $\mathrm{H}_{\mathrm{p}}, \mathrm{H}_{\mathrm{n}}$, and $\mathrm{H}_{\mathrm{m}}$ of the $\mathrm{BN}$ group. These results definitively confirm that the $\gamma$-CD is unidirectionally threaded onto the self-folded arm of BPC from its narrow rim. Due to the steric hindrance in the Vshaped molecule BPC, only one of the two arms of this moleculae can be encapsulated by $\gamma$-CD, although host exchanging between the two arms may exist. This pre-self-folded structure also reasonably explains the fact that $\beta-C D$ could bind the coumarin group in the reference compound PC but not in BPC (Figure S2, $\mathrm{SI})$. For comparison also, the one-arm reference compound NPC was further synthesized (Scheme 1). ITC experiments revealed a $1: 1$ stoichiometry in the binding interaction of this compound with $\gamma$-CD in water with an association constant of $\mathrm{K}_{\mathrm{a}}(1.3 \pm 0.1) \times 10^{4}$ $\mathrm{M}^{-1}$ (Figure S18, SI). Interestingly, similar ROE signals between the pyridinium naphthol (PyNOL) moiety, the coumarin group, and $\gamma$-CD in the 2D ROESY spectrum were observed (Figure S19, $\mathrm{SI})$, clearly indicating the formation of a folded host-guest complex between NPC and $\gamma$-CD, similar to that of BPCY. To find out whether the donor-acceptor stacking between PBN moiety and coumarin group is still possible when they are separatly present in aqueous sollution, we mixed the reference compounds BPM and PC together with $\gamma$-CD in $\mathrm{D}_{2} \mathrm{O}$, and recorded the 2D ROESY NMR spectrum. As can be seen in Figure S20 in the SI, only strong ROE signals between PBN and $\gamma$-CD, and negligible signals between coumarin and $\gamma$-CD were observed, while no correlations could be found between the PBN moiety and coumarin groups. These control experiments with the three reference compounds indicate that the flexible covalent linker between the donor and acceptor groups is necessary for achieving an effective intramolecular stacking, which is important for the subsequent encapsulation by $\gamma$-CD. a)

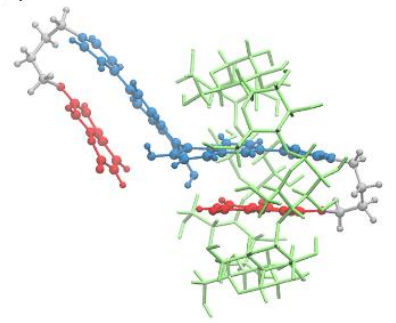

b)

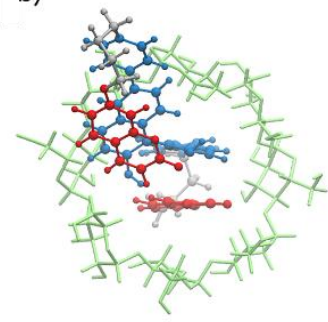

Figure 4. Simulated structure of the 1:1 complex BPCY. a) Side view and b) top view.

The structure of the complex BPCY was also investigated by computational simulations (see SI for details). The geometries of BPC and $\gamma$-CD were optimized by DFT calculations using the hybrid B3LYP functional ${ }^{20}$ and the double-zeta $6-31 \mathrm{G}(\mathrm{d})$ basis set. ${ }^{21}$ The electrostatic potentials of the two molecules were calculated at the HF/6-31G(d) level of theory, from which partial atomic charges were derived according to the restrained electrostatic potential (RESP) procedure. ${ }^{22}$ The bonded and nonbonded parameters were adopted from the general Amber force field (GAFF). ${ }^{23}$ Preliminary simulations in aqueous solution showed that the coumarin groups of BPC tend to form $\pi$ - $\pi$ stacked structures with the naphthol unit, which is in accordance with the NMR observations. Based on this fact we constructed the 1:1 hostguest structure of BPCY for MD simulations in aqueous solution and the final structure of this 1:1 host-guest complex BPCY is shown in Figure 4. Analysis on the interacting potential energies between BPC and $\gamma$-CD suggests that both van der Waals forces and Coulomb interactions stabilize the complex, in which the former play a more significant role (Figure S21, SI). In addition, hydrogen bonds are also formed between BPC and $\gamma$-CD, mostly between the coumarin group and $\gamma-\mathrm{CD}$, and occasionally between the $\mathrm{BN}$ moiety and $\gamma$-CD (Figure S22, SI). 
Optical spectroscopy studies. The experimental results and the computational simulations presented in the foregoing section have evidenced the formation of a 1:1 host-guest complex between BPC and $\gamma$-CD and have established the structure of this complex. In this section, the optical properties of this complex are presented. Figure 5 depicts the absorption spectra of BPC and the complex BPCY, as well as those of the reference compounds BPM and PC in aqueous medium. The spectrum of BPC shows three notable absorption peaks around $300 \mathrm{~nm}, 328 \mathrm{~nm}$ and $384 \mathrm{~nm}$, which can reasonably be assigned to the chromophore pieces contained in BPC as compared to the reference compounds BPM and PC. In this connection, it is worth mentioning that the one-arm reference compound NPC exhibits an almost identical spectrum as BPC, but with half the intensity. A more careful comparison reveals that, although BPC is composed of a PBN unit and two coumarin groups linked by flexible alkyl chains, the absorption spectral feature of this compound is different from that of the sum of the two individual chromophores, i.e., BPM and PC. A remarkable red-shift was observed for BPC as compared to BPM, especially for the peak at $\sim 384 \mathrm{~nm}$, indicating the possibility of a charge-transfer process. ${ }^{24}$

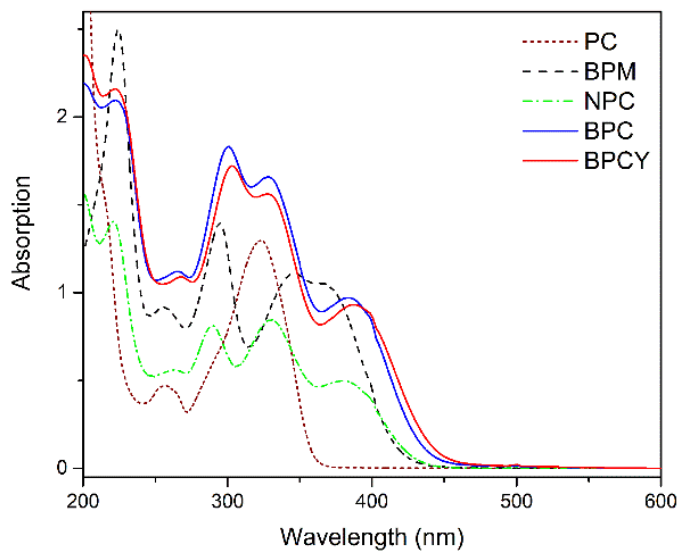

Figure 5. Absorption spectra of aqueous solutions of PC, BPM, NPC, BPC, and BPCY (BPC mixed with 10 equiv. of $\gamma-\mathrm{CD}$ ), $[\mathrm{PC}] / 2=$ $[\mathrm{BPM}]=[\mathrm{NPC}]=[\mathrm{BPC}]=0.04 \mathrm{mM}$.

This red shift in the absorption spectrum was reproduced by TD-DFT calculations and can be explained by the frontier molecular orbitals in BPM and BPC. As shown in Figure 6a, the HOMO-1 and $\mathrm{HOMO}$ of BPM are almost degenerate, and so are the LUMO and LUMO+1. The occupied and virtual molecular orbitals of BPM are more localized at the BN group and the pyridinium ion, respectively, rendering possible a binaphthol $->$ pyridinium charge transfer (CT) character in the low-lying excited states. While the HOMO-1 and HOMO of self-folded BPC differ completely from each other because of the participation of the coumarin in HOMO1 (Figure 6b), the LUMO and LUMO+1 of BPC are localized at each of the pyridinium units. This leads to a greater extent of intramolecular charge-transfer (ICT) in the low-lying excited states of BPC since the electron travels a longer distance in the HOMO $>$ LUMO+1 transition (Table 1). Also because coumarin contributes to the HOMO-1, the low-lying excitations of BPC show mixed binaphthol $\rightarrow$ pyridinium and coumarin $\rightarrow$ pyridinium chargetransfer characters, leading to a red-shifted absorption spectrum with respect to BPM, which is in agreement with the experimental results. Furthermore, such a red shift could be reversed by increasing the temperature of the BPC solution, because the ICT process is weakened at higher temperature and also due to the structural transition from the self-folded state to the stretched state of BPC molecule which extends the distance between the donor and acceptor groups (Figure S23, SI).

a) BPM
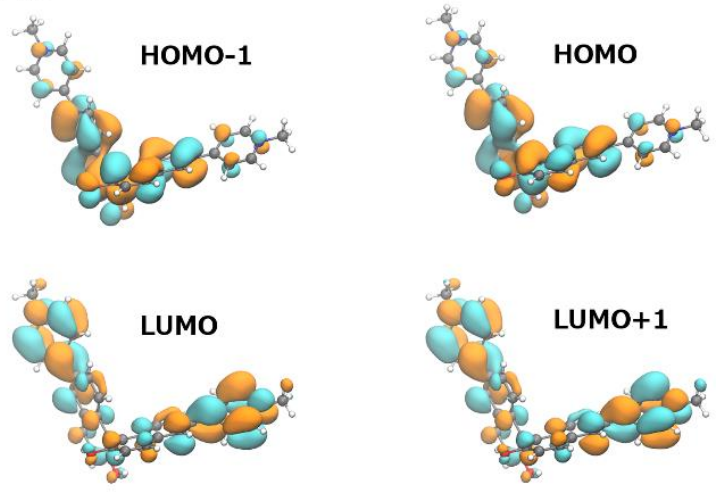

b) BPC
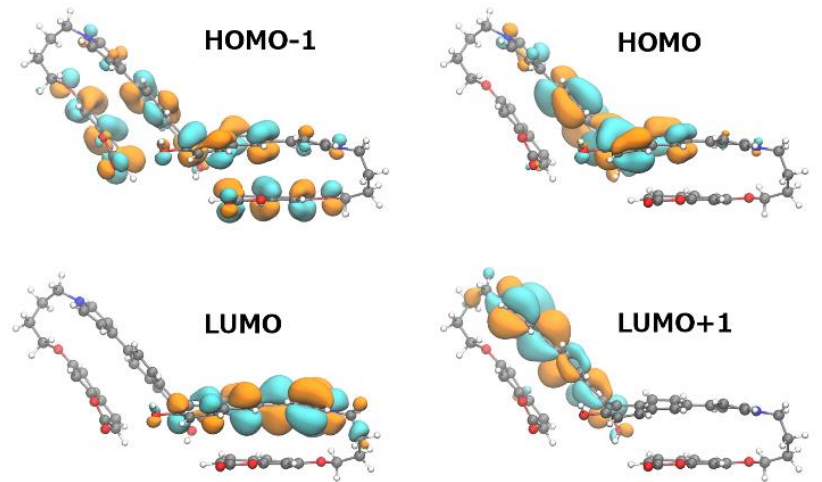

Figure 6. Frontier molecular orbitals of a) BPM and b) BPC.

Table 1. Computed excitation energies, oscillator strengths and molecular orbital compositions for the low-lying excited states of $\mathrm{BPC}$ and BPM.

\begin{tabular}{|c|c|c|c|c|}
\hline Compound & State & $\begin{array}{l}\text { Excitation } \\
\text { energy }\end{array}$ & $\begin{array}{l}\text { Oscillator } \\
\text { strength }\end{array}$ & MO composition \\
\hline \multirow[t]{4}{*}{ BPC } & \multirow[t]{2}{*}{$S_{1}$} & $3.24 \mathrm{eV}$ & \multirow{2}{*}{0.309} & $\mathrm{H} \rightarrow \mathrm{L}+1(75 \%)$ \\
\hline & & $383 \mathrm{~nm}$ & & $\mathrm{H}-1 \rightarrow \mathrm{L}+1(10 \%)$ \\
\hline & \multirow[t]{2}{*}{$\mathrm{S}_{2}$} & $3.25 \mathrm{eV}$ & \multirow{2}{*}{0.159} & $\mathrm{H}->\mathrm{L}(47 \%)$ \\
\hline & & $381 \mathrm{~nm}$ & & $\mathrm{H}-1$-> L (31\%) \\
\hline \multirow[t]{4}{*}{ BPM } & \multirow[t]{2}{*}{$S_{1}$} & $3.73 \mathrm{eV}$ & \multirow{2}{*}{0.762} & $\mathrm{H}->\mathrm{L}(49 \%)$ \\
\hline & & $332 \mathrm{~nm}$ & & $\mathrm{H}-1 \rightarrow \mathrm{L}+1(42 \%)$ \\
\hline & \multirow[t]{2}{*}{$\mathrm{S}_{2}$} & $3.76 \mathrm{eV}$ & \multirow{2}{*}{0.514} & $\mathrm{H} \rightarrow \mathrm{L}+1(48 \%)$ \\
\hline & & $329 \mathrm{~nm}$ & & $\mathrm{H}-1 \rightarrow \mathrm{L}(42 \%)$ \\
\hline
\end{tabular}

In subsequent experiments, fluorescence measurements were carried out, first with an aqueous BPC solution in the absence of any host molecules. As shown in Figure 7a, the fluorescence spectra of BPC exhibit apparent broad dual emissions, recognized as the PBN group emission at a shorter wavelength (blue-green band) and the coumarin $\rightarrow$ pyridinium ICT emission at a longer wave- 

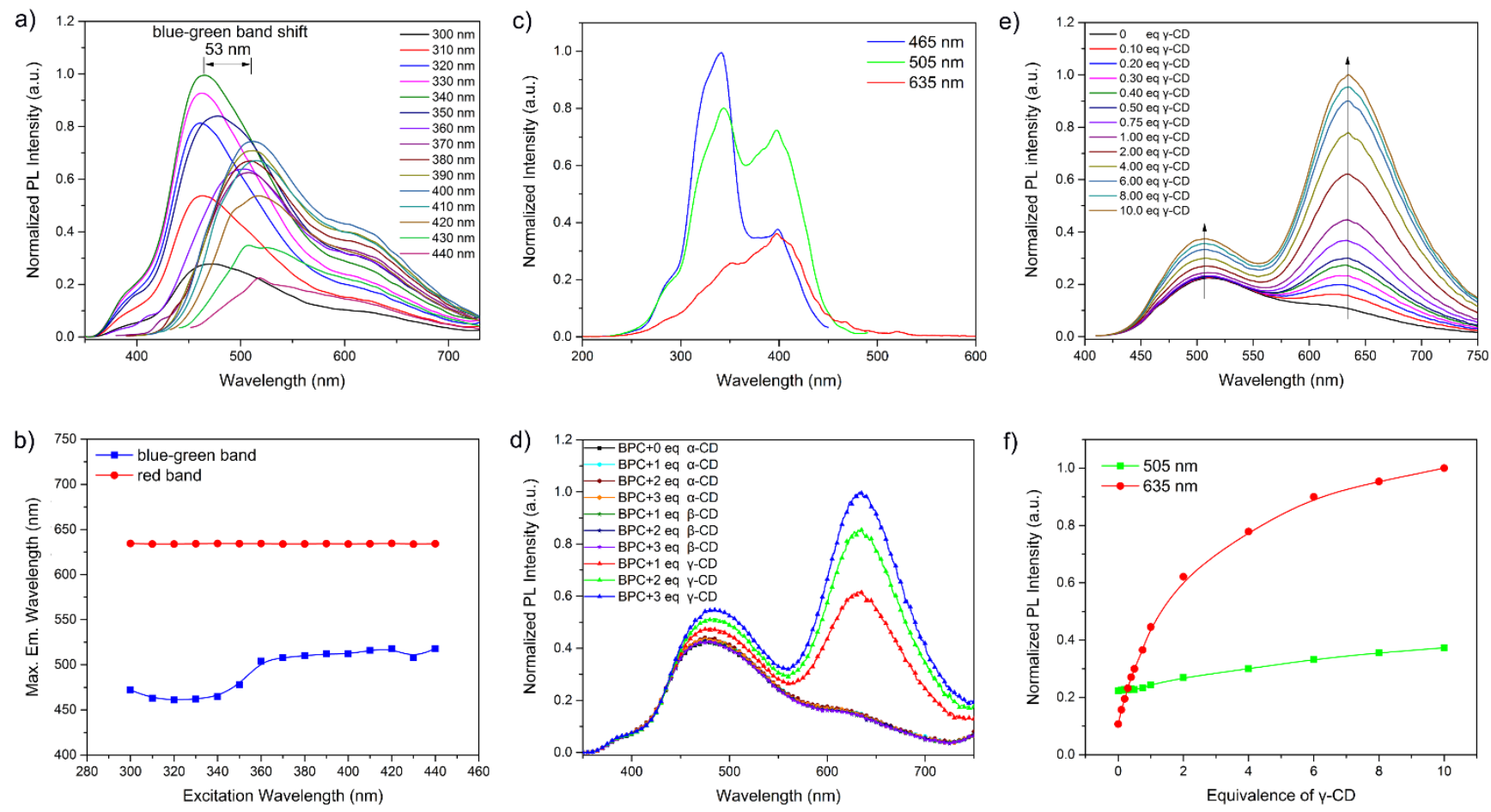

Figure 7. a) Fluorescence spectra of aqueous BPC solutions using various excitation wavelengths; b) Wavelengths of the blue-green band and the red band emission peaks as a function of the excitation wavelength; c) Fluorescence excitation spectra for BPC aqueous solutions monitored at 465 $\mathrm{nm}, 505 \mathrm{~nm}$ and $635 \mathrm{~nm}$; d) Fluorescence spectra of aqueous BPC solutions with different amount of $\alpha$-CD, $\beta$-CD, and $\gamma$-CD present, excited at 340 $\mathrm{nm}$; e) Fluorescence spectra of BPC solutions as a function of the amount of $\gamma$-CD, excitation was at $400 \mathrm{~nm}$; f) Relative intensity changes of the two emission peaks in panel e. $\left([\mathrm{BPC}]=0.04 \mathrm{mM}, 25^{\circ} \mathrm{C}\right)$

length (red band). We found that the emission maximum of the higher energy band (blue-green band) shifted (from $465 \mathrm{~nm}$ to 518 $\mathrm{nm})$ as a function of the excitation wavelength, while there was no significant shift for the red band emission peak $(\sim 635 \mathrm{~nm})$. As can be seen in Figure $7 b$, the curve for the red band emission remains nearly horizontal when the excitation wavelength is changed, whereas the curve for the wavelength of the blue-green band emission first decreases followed by a gradual increase until the excitation wavelength of $360 \mathrm{~nm}$ is reached, after which it roughly remains stable. The maximum value of the shift is as large as $53 \mathrm{~nm}$ (corresponding to an emission color change from blue to green).

According to Figure $7 \mathrm{a}$, the excitation controlled blue-green band shift is caused by two overlapping but noticeable emission peaks centered at circa $465 \mathrm{~nm}$ (blue band) and $505 \mathrm{~nm}$ (green band), suggesting the existence of two different excited states with different excitation energies. The blue emission is maximally excited at $340 \mathrm{~nm}$, while the excitation maximum for the green emission is at $400 \mathrm{~nm}$ (Figure 7c). To study the possible mechanism of this excitation-dependent dual emission behavior, a series of emission and excitation experiments was performed. Firstly, we measured the fluorescence spectrum of the coumarin derivative PC in water. When excited at the maximum excitation wavelength $(320 \mathrm{~nm})$, the aqueous PC solution was found to emit at $393 \mathrm{~nm}$. A similar result could barely be observed for the aqueous solution of BPC (Figure 7a) due to a possible Förster resonance energy transfer (FRET) or self-absorption quenching effect, as judged by the largely overlapping between the emission spectrum of PC and the excitation and absorption spectra of BPC (Figure S24, SI). If we further consider the maximum excitation wavelengths of the blue-green emission bands ( $340 \mathrm{~nm}$ and $400 \mathrm{~nm}$, Figure $7 \mathrm{c}$ ), we may conclude that these two emission bands are not caused by a coumarin monomer or its excimer. ${ }^{25}$ Secondly, we compared the excitationdependent fluorescence spectra of BPM, NCP (Figure S25, SI), and BPC (Figure 7a). We found that both the BPC and BPM displayed dual emission in the blue-green region when the excitation wavelength was changed, while the single-arm compound NPC only showed mono emission (green). This different behavior indicates that the blue emission most likely originates from the PBN unit. This is in line with the measured maximum excitation wavelength at $340 \mathrm{~nm}$, which is also observed for analogous pyridinyl binaphthol compounds. ${ }^{26}$ Hence, we tentatively assign this blue band as its locally excited state emission. Thirdly, we investigated again the excitation-dependent fluorescence spectra of BPM and NPC (Figure S25, SI) and compared these with the spectra of BPC. A common emission (green emission, $505 \sim 510 \mathrm{~nm}$ ) was found for all three compounds, indicating that a similar mechanism may be operative. Compounds BPM, NPC, and BPC, have one substructure in common, i.e. the PyNOL unit. This is a fluorophore with a typical charge-transfer characteristic feature (naphthol $\rightarrow$ pyridinium), ${ }^{24,27}$ which was also supported by the TD-DFT calculations mentioned above. The CT character was further proved by the observation of a typical negative solvatochromism effect in the absorption and emission spectra (Figure S26, S27, SI). Both spectra were found to display a blue shift when the polarity of the solvent was increased. This behavior is in agreement with literature reports on pyridinium containing donor-acceptor molecules for which it is mentioned that the dipole moment decreases in the excited state. ${ }^{28}$ Based on these results, it is reasonable to assign the green luminescence to an excited state CT emission. 
Based on the results discussed above, the blue-green color shift can now be rationalized by looking at the excitation spectra of the emission peaks. The relative intensities of these two peaks along with the red band emission intensity synergistically determine the shape and position of the apparent blue-green emission band. Figure $7 \mathrm{c}$ shows the excitation spectra of the blue $(465 \mathrm{~nm})$, green $(505 \mathrm{~nm})$ and red $(635 \mathrm{~nm})$ emission bands. When the excitation wavelength is below $350 \mathrm{~nm}$, the intensity of blue band emission is stronger than that of the green emission, hence the BPC solution mainly shows blue emission. After $350 \mathrm{~nm}$, the intensity of the green emission becomes predominant and the red emission also gradually becomes non-negligible, leading to a blue -> green -> yellow-green emission shift (Figure 8a). This is a quite interesting phenomenon which enables us to achieve reversible emission color switching simply by changing the excitation wavelength without the addition of any chemicals.

In separate experiments, it was tested how the host-guest interactions affected the PL emission. To this end, the fluorescence spectra of aqueous BPC solutions were recorded when they were titrated with CDs of different size ( $\alpha-C D, \beta-C D$ and $\gamma$-CD). As depicted in Figure $7 d$, the addition of $\alpha-C D$ and $\beta-C D$ had no effect on the PL spectra of the aqueous BPC solutions, which is consistent with the results of the binding studies mentioned above. On the other hand, both emission peaks at $480 \mathrm{~nm}$ and $635 \mathrm{~nm}$, especially the red band, were clearly enhanced when 1 or more equivs. of $\gamma$-CD were added. Such a remarkable enhancement of PL intensity again illustrates that efficient supramolecular interactions are present between BPC and $\gamma$-CD and that the coumarin $\rightarrow$ pyridinium charge-transfer process is greatly enhanced due to the involvement of $\gamma$-CD. Hence, we may conclude that according to the fluorescence measurements the guest molecule BPC shows a good size-selectivity for CDs as also reflected by both ITC and NMR experiments.

Figure $7 \mathrm{e}$ shows the fluorescence spectra of aqueous BPC solutions titrated with $\gamma$-CD when excited at $400 \mathrm{~nm}$, where both the blue-green band and the red band emission are maximally excited. In the absence of $\gamma$-CD, the spectra show a green emission peak $(\sim 505 \mathrm{~nm})$ as well as a very broad and weak ICT induced red emission peak $(\sim 635 \mathrm{~nm})$ with a Stokes shift as large as $235 \mathrm{~nm}$, which both dramatically increase in intensity when the amount of $\gamma$-CD is increased. The fluorescence intensities of the two peaks versus the amounts of $\gamma-\mathrm{CD}$ are plotted in Figure $7 \mathrm{f}$. As can be seen, the intensity of the red emission increases very rapidly between 0 and 1 equiv. of $\gamma$-CD, after which the curve roughly levels off, which is in agreement with the 1:1 binding stoichiometry confirmed above. The curves for the peaks at $\sim 505$ and $\sim 635 \mathrm{~nm}$ display different increasements as a function of added $\gamma$-CD, indicating the different effects that are induced by the host-guest complexation. When $\gamma$-CD captures one of the self-folded arms of BPC, the distance between the donor and the acceptor groups inside the cavity is shortened, thus favouring the charge-transfer process, as indicated by the further red-shift of the absorption peak (Figure 5). Furthermore, the lower polarity in the cavity of the $\gamma$ $\mathrm{CD}$, compared to bulk water, consequently decreases the nonradiative rates in the ICT state. ${ }^{29}$ All these facts, resulting from the encapsulation process, effectively reduce the nonradiative deactivation of the excited states, leading to the remarkable enhancement of the ICT emission (almost 10 times stronger according to the intensity at $635 \mathrm{~nm}$ when 10 equiv. of $\gamma$-CD is added, Figure 7e, 7f). Meanwhile, the hydrogen bonds between $\gamma$ -
$\mathrm{CD}$ and the hydroxy groups of binaphthol, the van der Waals forces between the host and the free arm of the guest, and the steric effect may also restrict the intramolecular rotation (RIR), forming a more rigid construction, as a result of which the blue-green band emission is also enhanced although not as effectively as the red band. It is of interest to compare the results discussed above with those obtained for the one-arm reference compound NPC, which cannot display RIR effects on the chiral axis. Upon binding with $\gamma$ $\mathrm{CD}$, a similar red emission enhancement was observed as for BPC, but at the expense of the green band emission (Figure S28, SI), due to the change in the CT process from naphthol $\rightarrow$ pyridinium to coumarin $->$ pyridinium $\mathrm{CT}$ processes.

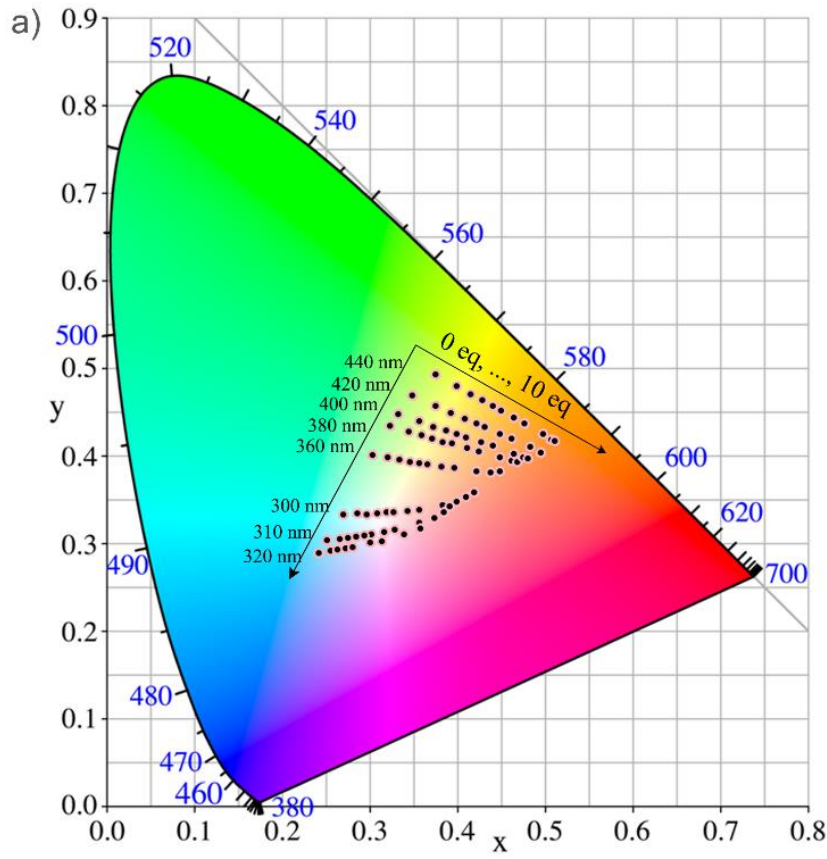

b)

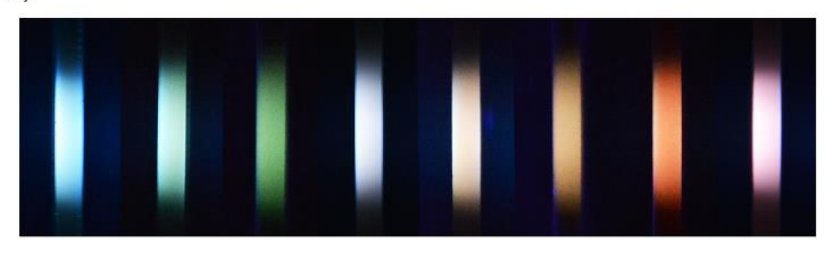

Figure 8. a) CIE 1931 chromaticity diagram. The black dots signify the luminescent color coordinates for BPC with various amounts of $\gamma$-CD present (from 0 to 10 equiv.) under different excitation wavelengths; $b$ ) Examples of fluorescence photographs of the BPC solutions under specific conditions according to a); $[$ BPC $]=0.04 \mathrm{mM}$.

As a control, we also measured the concentration-dependent fluorescence and UV-vis absorption spectra of the guest molecule BPC itself. As shown in Figure S29 in the SI, the shape and position of the peaks in the fluorescence spectra did not change much when the concentration of this compound was increased from $1.0 \times 10^{-6} \mathrm{M}$ to $5.0 \times 10^{-4} \mathrm{M}$, which is 12.5 times larger than the concentration used for the experiments displayed in Figure 7e. The concentration independence of the fluorescence spectra indicates that the excited states of BPC don't change from the dispersed state to the aggregated state. In addition, to see whether the binding between $\gamma$-CD and the dispersed BPC molecule will exhibit different fluorescent characteristics or not, compared with the aggregated state (Figure 7e), we also measured the fluorescence spectra of 
BPC solution at very low concentration ( $1 \mu \mathrm{M}$, below CMC) and titrated with $\gamma$-CD. As shown in Figure S30 in SI, although the fluorescence intensity is relatively low at such dilute solution, the trend is the same as observed in the concentrated solution, that is the intensities of both the blue-green band and the red band emission are enhanced by the addition of $\gamma$-CD in an analogous way. Therefore the mechanisms for the emission, and the interactions between the BPC molecule and $\gamma$-CD should be the same in the dispersed and aggregated states. Hence the fluorescent property is not likely coming from the aggregated material but from the fundamental interactions in the single host-guest complex between BPC and $\gamma$-CD. Moreover, the absorption spectra of the BPC solution did not show any red-shift when the concentration was increased from below CMC to above CMC $(1 \mu \mathrm{M} \sim 80 \mu \mathrm{M}$, Figure S31a, SI), which was different from the effect of adding $\gamma$-CD. Further, the absorption intensity at $384 \mathrm{~nm}$ increases linearly with the increase of concentration (Figure S31b). Hence these solutions perfectly fit the Beer-Lambert law in the measured concentrations, which is a rule for solutions that without obvious interactions between solute molecules. As a result, we reasonably deduce that the aggregates may be loose and dynamic, and the aggregation does not cause any obvious interactions between BPC molecules at the electronic ground state in our experimental condition. The concentration independences of both the fluorescence and absorption spectra indicate that the interesting optical behavior of BPC is not the result of the formation of either an intermolecular excimer or another ground state aggregate, but originates from the BPC molecule itself and its host-guest binding interactions with $\gamma$ CD.

Stimulated by the observed dual-mode tunable PL emission (i.e. by the excitation wavelength and $\gamma-\mathrm{CD}$ ), we finally measured the fluorescence spectra of aqueous BPC solutions in an orthogonal fashion, i.e. by using various amounts of $\gamma$-CD $(0 \sim 10$ equiv. $)$ and different excitation wavelengths $(300 \sim 440 \mathrm{~nm})$. Hundreds of scans were performed and all the luminescent color coordinates were calculated and plotted in the CIE 1931 chromaticity diagram. As can be seen in Figure 8a, the aqueous solutions of BPC and the complex exhibit amazing colorful emission capacities, i.e. red (R), green (G), and blue (B) colors, as well as the intermediate colors (yellow, orange, etc.) can be achieved by applying specific conditions. Several examples of the obtained luminescence photographs are shown in Figure $8 \mathrm{~b}$. Notably, almost pure whitelight emission $(0.33,0.34)$ could be realized when BPC was combined with 0.5 equiv. of $\gamma-\mathrm{CD}$ and excited at $300 \mathrm{~nm}$ (see the coordinates in Figure 8a).

It is well known that chiral luminescent compounds and materials may display circularly polarized luminescence (CPL). ${ }^{30}$ Given the fact that our compounds possess a chiral binaphthol moiety, we investigated the CPL properties of BPC and BPCY in aqueous solution. As shown in Figure S32a in SI, BPC exhibits a CPL signal at the main emission band centered around $505 \mathrm{~nm}$ with a degree of circular polarization $g_{\text {lum }}=-(1.0 \pm 0.1) \times 10^{-3}$. The latter dissymmetry ratio is defined as

$$
g_{\text {lum }}=\frac{I_{\mathrm{L}}-I_{\mathrm{R}}}{2\left(I_{\mathrm{L}}+I_{\mathrm{R}}\right)}
$$

where $I_{\mathrm{L}}$ and $I_{\mathrm{R}}$ are the intensities of the left and right circularly polarized fluorescence emissions, respectively. This dissymmetry ratio $g_{l u m}$ for the fluorescence can be compared to the dissymmetry ratio $g_{\text {abs }}=-0.5 \times 10^{-3}$, calculated from the long wavelength absorp- tion band in the circular dichroism (CD) spectrum of BPC (Figure S33, SI). The similarity in sign and magnitude of these dissymmetry ratios is consistent with the idea that the main fluorescence band of BPC originates from an excited state related to the twisted rigid arms in the PBN moiety. We found that upon addition of $\gamma$-CD, the chirality of the ground state only changed a little according to the CD spectra, simultaneously, the circular polarization effect in the above mentioned emission band was also largely maintained (Figure S32b). For the long wavelength emission band near 635 $\mathrm{nm}$ we measured a vanishingly small degree of circular polarization. This observation is in line with our assignment above, i.e. that the emission originates from the excited state charge transfer from the flexibly linked coumarin unit to pyridinium group, which does not directly involve the binaphthol core.

\section{CONCLUSION}

We have successfully constructed a unique host-guest system, which is composed of $\gamma$-CD as the host and a two-arm self-folded $\mathrm{D}_{1}-\mathrm{A}^{+} \sim \mathrm{D}_{2}$ type fluorophore BPC containing a PBN unit and a coumarin group at each arm linked by flexible alkyl chains as the guests. Detailed ITC, DLS, 2D NMR, MS, and spectroscopic studies along with molecular dynamics simulations revealed that BPC can form loose and dynamic aggregate at concentration above $4 \mu \mathrm{M}$ in water. $\gamma$-CD can form host-guest complex with the aggregated state as well as the dispersed state of BPC molecules in aqueous solution a 1:1 stoichiometry. We confirmed the optical behavior observed in this work was not induced by the aggregation of BPC, but mainly originated from the host-guest complex between BPC and $\gamma$-CD. This complex has a distinct asymmetric structure in which the $\gamma$-CD host captures one of the arms of the guest from its narrow rim side to fit this molecular in a $\mathrm{V}$-type geometry. A variety of supramolecular interactions, including hydrophobic effects, van der Waals interactions, Coulomb interactions, and hydrogen bonding synergistically stablize the complex. Aqueous solutions of the complex between BPC and $\gamma$ CD exhibit apparent dual-emission bands, namely a blue-green band and a red band, which can be modulated in a dual mode fashion by varying the excitation wavelength and the concentration of $\gamma$-CD. The proposed operation mechanisms of the host-guest system is based on spectroscopic studies and frontier molecular orbital calculations. Although multicolor emission has already been achieved successfully with inorganic luminescent complexes, especially quantum dot hybrid materials, we believe that supramolecular chemistry may offer another approach to materials exhibiting multicolor and white light emission. An advantage is that these supramolecular materials can be easily modified and may display multi stimuli-responsive properties due to the dynamic nature of noncovalent interactions. The rationale behind the molecular design and the host-guest complexation reported here may not only provide important insights in donor-acceptor and host-guest interactions but also inspire scientists to construct other advanced optical materials by supramolecular approaches. Furthermore, the unique multicolor emission including red (R), green $(\mathrm{G})$, blue (B), and the various intermediate colors, especially white-light emission, which is achieved using a single supramolecular host-guest complex, may hold promise for applications in the fields of information processing and display technology.

\section{ASSOCIATED CONTENT}


Supporting Information. Detailed experiments, additional spectroscopic data and computational simulations details. This material is available free of charge via the Internet at http://pubs.acs.org.

\section{AUTHOR INFORMATION}

\section{Corresponding Author}

*maxiang@ecust.edu.cn

*tianhe@ecust.edu.cn

\section{Author Contributions}

${ }^{*}$ These authors contributed equally to this work.

\section{ACKNOWLEDGMENT}

Support from the Programme of Introducing Talents of Discipline to Universities (B16017), the NSFC/China (21476075, 21421004 and 21272072), the National Basic Research 973 Program, the Fundamental Research Funds for the Central Universities, the Netherlands Ministry of Education, Culture and Science (Gravitation program 024.001.035), and the European Research Council (ERC Advanced grant ALPROS-290886) is gratefully acknowledged. X.L. and H.Å. thank the Swedish National Infrastructure for Computing (SNIC) for providing computational resources for project SNIC 2015/16-10. The authors also thank Prof. Stefan C. J. Meskers from Eindhoven University of Technology for the CPL measurements, and Dr. Zhiyun Zhang, Dr. Boxue Tian and Dr. Jialiang Xu for helpful discussions.

\section{REFERENCES}

(1) (a) Balzani, V.; Credi, A.; Ratmo, F. M.; Stoddart, J. F. Angew. Chem. Int. Ed. 2000, 39, 3348. (b) Lehn, J.-M. Science 2002, 295, 2400. (c) Thordarson, P.; Bijsterveld, E. J. A.; Rowan, A. E.; Nolte, R. J. M. Nature 2003, 424, 915. (d) Aida, T.; Meijer, E. W.; Stupp, S. I. Science 2012, 335, 813. (e) Lewandowski, B.; De Bo, G.; Ward, J. W.; Papmeyer, M.; Kuschel, S.; Aldegunde, M. J.; Gramlich, P. M. E.; Heckmann, D.; Goldup, S. M.; D’Souza, D. M.; Fernandes, A. E.; Leigh, D. A. Science 2013, 339, 189. (f) Szymański, W.; Beierle, J. M.; Kistemaker, H. A. V.; Velema, W. A.; Feringa, B. L. Chem. Rev. 2013, 113, 6114. (g) Fiore, G. L.; Rowan, S. J.; Weder, C. Chem. Soc. Rev. 2013, 42, 7278. (h) Durola, F.; Heitz, V.; Reviriego, F.; Roche, C.; Sauvage, J.-P.; Sour, A.; Trolez, Y. Acc. Chem. Res. 2014, 47, 633. (i) Zhang, Q.; Tian, H. Angew. Chem. Int. Ed. 2014, 53, 10582. (j) Baker, M. B.; Albertazzi, L.; Voets, I. K.; Leenders, C. M. A.; Palmans, A. R. A.; Pavan, G. M.; Meijer, E. W. Nat. Commun. 2015, 6, 6234. (k) Cook, T. R.; Stang, P. J. Chem. Rev. 2015, 115, 7001. (1) Qu, D.-H.; Wang, Q.-C.; Zhang, Q.-W.; Ma, X.; Tian, H. Chem. Rev. 2015, 115, 7543. (m) Xue, M.; Yang, Y.; Chi, X.; Yan, X.; Huang, F. Chem. Rev. 2015, 115, 7398. (n) Yang, L.; Tan, X.; Wang, Z.; Zhang, X. Chem. Rev. 2015, 115, 7196. (o) Neuhaus, P.; Cnossen, A.; Gong, J. Q.; Herz, L. M.; Anderson, H. L. Angew. Chem. Int. Ed. 2015, 54, 7344. (p) Heinrich, T.; Traulsen, C. H. H.; Holzweber, M.; Richter, S.; Kunz, V.; Kastner, S. K.; Krabbenborg, S. O.; Huskens, J.; Unger, W. E. S.; Schalley, C. A. J. Am. Chem. Soc. 2015, 137, 4382. (q) Kim, D. S.; Chang, J.; Leem, S.; Park, J. S.; Thordarson, P.; Sessler, J. L. J. Am. Chem. Soc. 2015, 137, 16038.

(2) (a) Kim, H. N.; Guo, Z.; Zhu, W.; Yoon, J.; Tian, H. Chem. Soc. Rev. 2011, 40, 79. (b) An, B.-K.; Gierschner, J.; Park, S. Y. Acc. Chem. Res. 2012, 45, 544. (c) Maggini, L.; Bonifazi, D. Chem. Soc. Rev. 2012, 41, 211. (d) Inouye, M.; Hayashi, K.; Yonenaga, Y.; Itou, T.; Fujimoto, K.; Uchida, T.-a.; Iwamura, M.; Nozaki, K. Angew. Chem. Int. Ed. 2014, 53, 14392. (e) Ryan, S. T. J.; Del Barrio, J.; Ghosh, I.; Biedermann, F.; Lazar, A. I.; Lan, Y.; Coulston, R. J.; Nau, W. M.; Scherman, O. A. J. Am. Chem. Soc. 2014, 136, 9053. (f) Zhou, X.; Lee, S.; Xu, Z.; Yoon, J. Chem. Rev. 2015, 115, 7944. (g) You, L.; Zha, D.; Anslyn, E. V. Chem. Rev. 2015, 115, 7840. (h) Lu, H.; Zheng, Y.; Zhao, X.; Wang, L.; Ma, S.; Han, X.; Xu, B.; Tian, W.; Gao, H. Angew. Chem. Int. Ed. 2015, 55, 155. (i) Yamashina, M.; Sartin, M. M.; Sei, Y.; Akita, M.; Takeuchi, S.; Tahara, T.; Yoshizawa, M. J. Am. Chem. Soc. 2015, 137, 9266. (j) Park, S. K.; Cho, I.; Gierschner, J.; Kim, J. H.; Kim, J.
H.; Kwon, J. E.; Kwon, O. K.; Whang, D. R.; Park, J.-H.; An, B.-K.; Park, S. Y. Angew. Chem. Int. Ed. 2016, 55, 203.

(3) (a) Zhu, L.; Ang, C. Y.; Li, X.; Nguyen, K. T.; Tan, S. Y.; Ågren, H.; Zhao, Y. Adv. Mater. 2012, 24, 4020. (b) Yang, Q.-Y.; Lehn, J.-M. Angew. Chem. Int. Ed. 2014, 53, 4572. (c) Aizawa, N.; Pu, Y.-J.; Watanabe, M.; Chiba, T.; Ideta, K.; Toyota, N.; Igarashi, M.; Suzuri, Y.; Sasabe, H.; Kido, J. Nat. Commun. 2014, 5, 5756. (d) Shang, M.; Li, C.; Lin, J. Chem. Soc. Rev. 2014, 43, 1372. (e) Chen, P.; Li, Q.; Grindy, S.; Holten-Andersen, N. J. Am. Chem. Soc. 2015, 137, 11590. (f) Zhu, L.; Trinh, M. T.; Yin, L.; Zhang, Z. Chem. Sci. 2015, 7, 2058. (g) Yang, Y.; Lowry, M.; Schowalter, C. M.; Fakayode, S. O.; Escobedo, J. O.; Xu, X.; Zhang, H.; Jensen, T. J.; Fronczek, F. R.; Warner, I. M.; Strongin, R. M. J. Am. Chem. Soc. 2006, 128, 14081. (h) Xie, Z.; Chen, C.; Xu, S.; Li, J.; Zhang, Y.; Liu, S.; Xu, J.; Chi, Z. Angew. Chem. Int. Ed. 2015, 54, 7181.

(4) (a) Yu, G.; Yin, S.; Liu, Y.; Chen, J.; Xu, X.; Sun, X.; Ma, D.; Zhan, X.; Peng, Q.; Shuai, Z.; Tang, B.; Zhu, D.; Fang, W.; Luo, Y. J. Am. Chem. Soc. 2005, 127, 6335. (b) Mei, J.; Leung, N. L. C.; Kwok, R. T. K.; Lam, J. W. Y.; Tang, B. Z. Chem. Rev. 2015, 115, 11718. (c) Bu, F.; Duan, R; Xie, Y.; Yi, Y.; Peng, Q.; Hu, R.; Qin, A.; Zhao, Z.; Tang, B. Z. Angew. Chem. Int. Ed. 2015, 54, 14492.

(5) Liu, X.; Xu, D.; Lu, R.; Li, B.; Qian, C.; Xue, P.; Zhang, X.; Zhou, H. Chem. - Eur.J.2011, 17, 1660.

(6) (a) Li, J.; Song, F.; Wang, L.; Jiao, J.; Cheng, Y.; Zhu, C. Macromol. Rapid Commun. 2012, 33, 1268. (b) Rong, Y.; Wu, C.; Yu, J.; Zhang, X.; Ye, F.; Zeigler, M.; Gallina, M. E.; Wu, I. C.; Zhang, Y.; Chan, Y.-H.; Sun, W.; Uvdal, K.; Chiu, D. T. ACS Nano 2013, 7, 376.

(7) de Jesus, R. A.; da Luz, L. L.; Santos, D. O.; Costa, J. A. S.; Navickiene, S.; Gatto, C. C.; Junior, S. A.; de Mesquita, M. E. Dalton Trans. 2015, 44, 17318.

(8) (a) Bardelang, D.; Zaman, M. B.; Moudrakovski, I. L.; Pawsey, S.; Margeson, J. C.; Wang, D.; Wu, X.; Ripmeester, J. A.; Ratcliffe, C. I.; Yu, K. Adv. Mater. 2008, 20, 4517. (b) Song, J.; Li, J.; Li, X.; Xu, L.; Dong, Y.; Zeng, H. Adv. Mater. 2015, 27, 7162.

(9) (a) Zhao, Y. S.; Fu, H.; Peng, A.; Ma, Y.; Liao, Q.; Yao, J. Acc. Chem. Res. 2010, 43, 409. (b) Wang, F.; Liu, X. Acc. Chem. Res. 2014, 47, 1378.

(10) (a) Cusido, J.; Deniz, E.; Raymo, F. M. Eur. J. Org. Chem. 2009, 2009, 2031. (b) Chen, O.; Shelby, D. E.; Yang, Y.; Zhuang, J.; Wang, T.; Niu, C.; Omenetto, N.; Cao, Y. C. Angew. Chem. Int. Ed. 2010, 49, 10132.

(11) Chevreux, S.; Allain, C.; Wilbraham, L.; Nakatani, K.; Jacques, P.; Ciofini, I.; Lemercier, G. Faraday Discussions 2015, 185, 285.

(12) (a) Sagara, Y.; Komatsu, T.; Terai, T.; Ueno, T.; Hanaoka, K.; Kato, T.; Nagano, T. Chem. -Eur. J. 2014, 20, 10397. (b) Sagara, Y.; Yamane, S.; Mitani, M.; Weder, C.; Kato, T. Adv. Mater. 2015, 28, 1073.

(13) (a) Su, H.-C.; Chen, H.-F.; Fang, F.-C.; Liu, C.-C.; Wu, C.-C.; Wong, K.-T.; Liu, Y.-H.; Peng, S.-M. J. Am. Chem. Soc. 2008, 130, 3413. (b) Abbel, R.; Grenier, C.; Pouderoijen, M. J.; Stouwdam, J. W.; Leclère, P. E. L. G.; Sijbesma, R. P.; Meijer, E. W.; Schenning, A. P. H. J. J. Am. Chem. Soc. 2009, 131, 833. (c) Molla, M. R.; Ghosh, S. Chem. -Eur.J. 2012, 18, 1290. (d) Zhang, B.; Yong, G.; Zhao, Y.; Zhang, X. Opt. Mater. 2013, 36, 191. (e) Song, S.; Zheng, H.-F.; Li, D.-M.; Wang, J.-H.; Feng, H.-T.; Zhu, Z.-H.; Chen, Y.-C.; Zheng, Y.-S. Org. Lett. 2014, 16, 2170. (f) Yan, X.; Cook, T. R.; Wang, P.; Huang, F.; Stang, P. J. Nat. Chem. 2015, 7, 342. (g) Martínez-Calvo, M.; Kotova, O.; Möbius, M. E.; Bell, A. P.; McCabe, T.; Boland, J. J.; Gunnlaugsson, T. J. Am. Chem. Soc. 2015, 137, 1983.

(14) (a) Zhang, Z.; Xu, B.; Su, J.; Shen, L.; Xie, Y.; Tian, H. Angew. Chem. Int. Ed. 2011, 50, 11654. (b) Yao, X.; Ma, X.; Tian, H. J. Mater. Chem. C2014, 2, 5155.

(15) Huang, W.; Sun, L.; Zheng, Z.; Su, J.; Tian, H. Chem. Commun. 2015, 51, 4462 .

(16) Zhang, Z.; Wu, Y.-S.; Tang, K.-C.; Chen, C.-L.; Ho, J.-W.; Su, J.; Tian, H.; Chou, P.-T. J. Am. Chem. Soc. 2015, 137, 8509.

(17) (a) Sun, R.; Xue, C.; Ma, X.; Gao, M.; Tian, H.; Li, Q. J. Am. Chem. Soc. 2013, 135, 5990. (b) Zhang, Q.; Qu, D.-H.; Wu, J.; Ma, X.; Wang, Q.; Tian, H. Langmuir 2013, 29, 5345. (c) Zhang, Q.; Qu, D.-H.; Ma, X.; Tian, H. Chem. Commun. 2013, 49, 9800. (d) Zhang, Q.; Yao, X.; $\mathrm{Qu}, \mathrm{D}$.; Ma, X. Chem. Commun. 2014, 50, 1567. (e) Ma, X.; Tian, H. Acc. Chem. Res. 2014, 47, 1971. 
(18) (a) Nepogodiev, S. A.; Stoddart, J. F. Chem. Rev. 1998, 98, 1959. (b) Löwe, C.; Weder, C. Adv. Mater. 2002, 14, 1625. (c) Wenz, G.; Han, B.-H.; Müller, A. Chem. Rev. 2006, 106, 782. (d) Boekhoven, J.; Rubert Pérez, C. M.; Sur, S.; Worthy, A.; Stupp, S. I. Angew. Chem. Int. Ed. 2013, 52, 12077. (e) Chen, H.; Ma, X.; Wu, S.; Tian, H. Angew. Chem. Int. Ed. 2014, 53, 14149. (f) Harada, A.; Takashima, Y.; Nakahata, M. Acc. Chem. Res. 2014, 47, 2128. (g) Delbianco, M.; Bharate, P.; Varela-Aramburu, S.; Seeberger, P. H. Chem. Rev. 2015, 116, 1693. (h) Sun, H.-L.; Chen, Y.; Zhao, J.; Liu, Y. Angew. Chem. Int. Ed.2015, 54, 9376.

(19) Moorthy, J. N.; Venkatesan, K.; Weiss, R. G. J. Org. Chem. 1992, $57,3292$.

(20) (a) Lee, C.; Yang, W.; Parr, R. G. Phys. Rev. B 1988, 37, 785. (b) Becke, A. D. J. Chem. Phys. 1993, 98, 5648.

(21) Hehre, W. J.; Ditchfield, R.; Pople, J. A. J. Chem. Phys. 1972, 56, 2257.

(22) Bayly, C. I.; Cieplak, P.; Cornell, W.; Kollman, P. A. J. Phys. Chem. 1993, 97, 10269.

(23) Wang, J.; Wolf, R. M.; Caldwell, J. W.; Kollman, P. A.; Case, D. A. J. Comput. Chem. 2004, 25, 1157.

(24) Grabowski, Z. R.; Rotkiewicz, K.; Rettig, W. Chem. Rev. 2003, 103, 3899.

(25) Liu, T.-J.; Wu, S.-K. Acta Phys. -Chim. Sin. 1996, 12, 677.

(26) (a) Lee, S. J.; Kim, J. S.; Lin, W. Inorg. Chem. 2004, 43, 6579. (b) Li, Z.-B.; Lin, J.; Zhang, H.-C.; Sabat, M.; Hyacinth, M.; Pu, L. J. Org. Chem. 2004, 69, 6284 .

(27) Röcker, C.; Heilemann, A.; Fromherz, P. J. Phys. Chem. 1996, 100, 12172

(28) (a) Carlotti, B.; Consiglio, G.; Elisei, F.; Fortuna, C. G.; Mazzucato, U.; Spalletti, A. J. Phys. Chem. A 2014, 118, 3580. (b) Carlotti, B.; Cesaretti, A.; Fortuna, C. G.; Spalletti, A.; Elisei, F. Phys. Chem. Chem. Phys. 2015, $17,1877$.

(29) Bhattacharyya, K.; Chowdhury, M. Chem. Rev. 1993, 93, 507.

(30) (a) Riehl, J. P.; Richardson, F. S. Chem. Rev. 1986, 86, 1. (b) Satrijo, A.; Meskers, S. C. J.; Swager, T. M. J. Am. Chem. Soc. 2006, 128, 9030. (c) Sánchez-Carnerero, E. M.; Moreno, F.; Maroto, B. L.; Agarrabeitia, A. R.; Ortiz, M. J.; Vo, B. G.; Muller, G.; Moya, S. d. 1. J. Am. Chem. Soc. 2014, 136, 3346. (d) Nakabayashi, K.; Amako, T.; Tajima, N.; Fujiki, M.; Imai, Y. Chem. Commun. 2014, 50, 13228. (e) Kumar, J.; Nakashima, T.; Kawai, T. J. Phys. Chem. Lett. 2015, 6, 3445. 
Table of Contents artwork

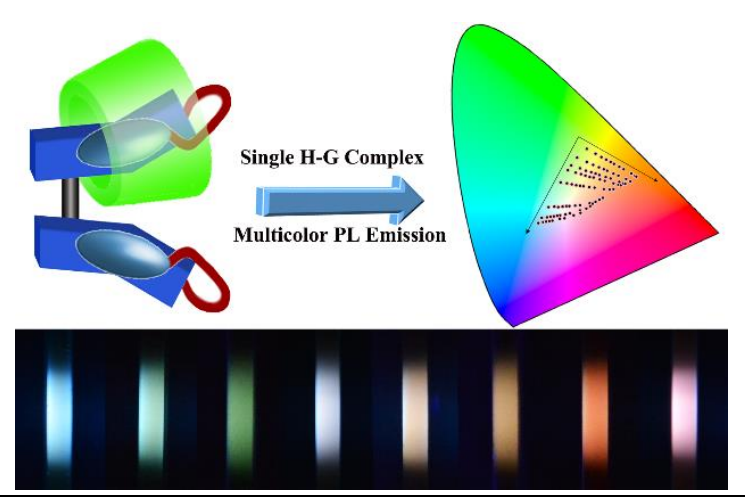

